\title{
AN IMPROVED METHOD OF COLLECTING GASES FROM THE MERCURY PUMP.
}

BY FREDERICK G. KEYES.

Received October 4, Io09.

The usual method of collecting gases from the mercury pump is to invert a tube filled with mercury over the end of the pump capillary. The writer wishes to point out the reason why this method is unsuitable in exact work and to describe an arrangement which overcomes the difficulties to be mentioned, simplifies the manipulation and enables the operator to obtain a high vacuum more easily, if necessary.

In the writer's work, ${ }^{1}$ it was required to transfer gases through the mercury pump into an inverted tube and then to transfer the gases to the gas analysis apparatus. In carrying out this latter operation it was noticed that even when great care was exercised in filling and inverting a perfectly clean collecting tube of $100 \mathrm{~cm}$. capacity, minute bubbles were trapped. The presence of a film of air between the mercury and the glass walls of the collecting tube may le demonstrated by setting the lower end of the tube upon a rubber stopper set into the bottom of the mercury trough and communicating, by means of a rubber tube, with a mercury reservoir. Upon lowering the reservoir the mercury will fall in the tube, producing a Torricellian vacuum. As the mercury falls bubbles of air will be observed to start from the walls of the tube and pass along the walls into the Torricellian vacuum. When the mercury reservoir is raised and the pressure within the tube restored to that of the atmosphere, it will be found that an appreciable quantity of air has been freed from the walls of the tube.

When operating a mercury pump of $500\left(\mathrm{~cm}^{2}\right)$ capacity, having a capillary of about I $\mathrm{mm}$. width, the bubbles passing down the capillary will be about I mm. long. (The writer ventures to suggest, as a result of his experience, that capillaries as small in bore as $1 / 2 \mathrm{~mm}$. are to be preferred.) Now as the vacuum improves the difficulty of removing the air collected by the mercury rising in the pump head increases. To obviate this difficulty Morley ${ }^{2}$ adopted the expedient of connecting a piston pump to the pump capillary and thus, by reducing the pressure on the capillary side, materially increased the size of the bubbles passing down the capillary. The modification represented in the figures is calculated to obviate the difficulties mentioned above.

It is customary to allow the end of the capillary O (Fig. I) to dip beneath the surface of the mercury trough, placing the inverted tubes intended for collecting the gas over the upturned end of the capillary. Instead of this, the tube $\mathrm{D}-\mathrm{D}^{\prime}$ is sealed directly to the upturned end of

${ }^{1}$ Keyes, American Journal of Medical Research, 2I, 69.

${ }^{2}$ Smithsonian Contributions, Vol, 29, p. 17. 
the capillary. A trap is also sealed to the bottom of $D^{\prime}$. From the end of the trap communication is made with a mercury reservoir by means of rubber tubing. 'To the upper end of $D^{\prime}$ is sealed a three-way stopcock provided with capillary leads. This latter may be constructed after the plan of the vacuum stopcock ${ }^{1}$ as an extra precaution if desired. When it is a question of simple exhaustion, $L$ is left open to the atmosphere with the mercury level as represented in the figure during the first few strokes. Toward the end of an exhaustion the reservoir may be raised to expel the air within $D^{\prime}$ and again lowered. This will leave a fair vacuum in $\mathrm{D}^{\prime}$, into which the bubbles passing down the pump capillary will be discharged.

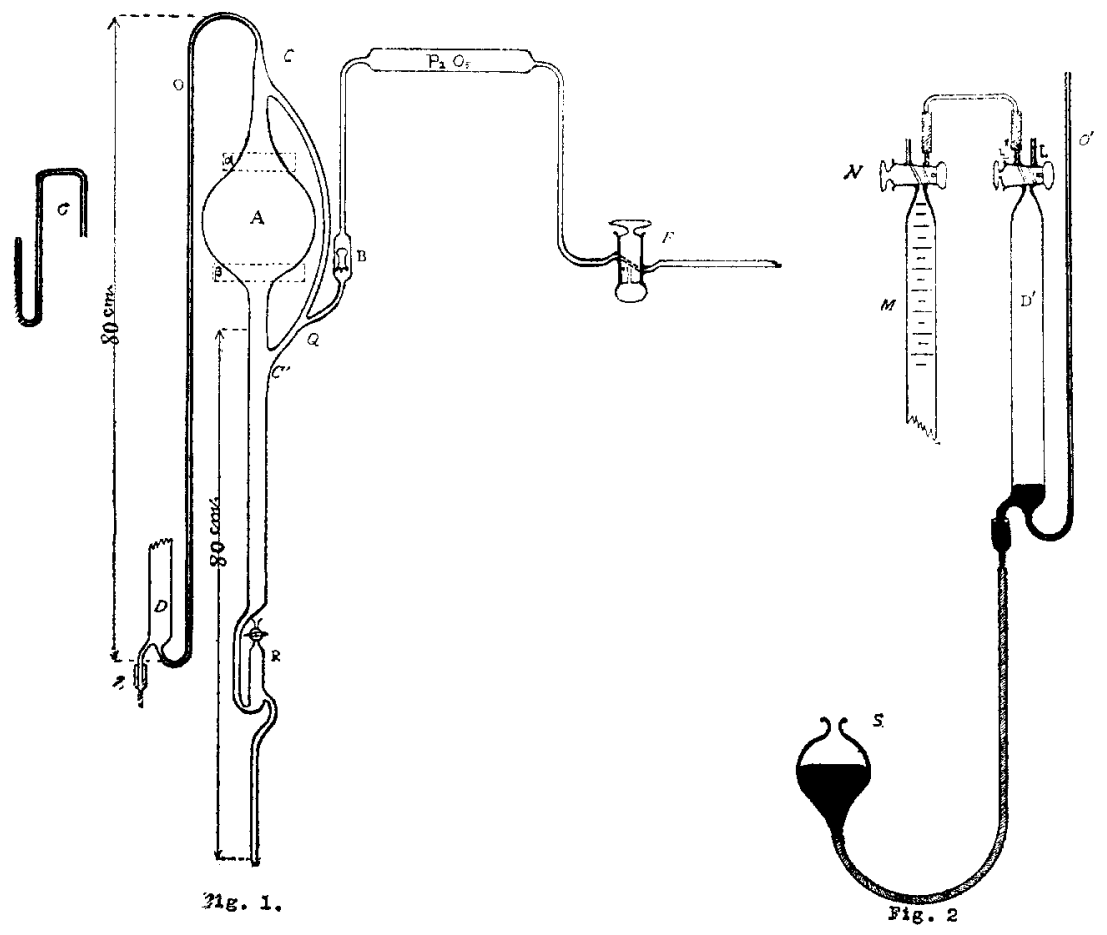

The collection of gases by means of the apparatus is very simple. When the gases are ready to be collected the gas burette $\mathrm{M}$ is connected after the manner represented in Fig. 2. The air is passed over from the burette into the collecting tube by raising the burette leveling tube. The burette stopcock may be closed and the air from the gas burette walls collected by lowering the leveling tube and subsequently pressing the gas over into $D^{\prime}$. The air from $D^{\prime}$ may be pressed out by turning the stopcock at the top of $D^{\prime}$ so that it communicates with $L$. If the reservoir $S$ is now

${ }^{1}$ Keyes, Science, 28, 735. 
lowered until the mercury passes completely out of $D^{\prime}$ and again raised, the air in contact with the walls may be passed out of $\mathrm{L}$. By repeating the above-described operations several times the collecting tube is obtained practically free from gas. The gases to be collected are pumped directly into $D^{\prime}$. At the conclusion of the pumping the gases may be passed over into the gas burette $M$ by raising the reservoir and manipulating the stopcocks. Any minute bubbles which may have lodged between the mercury and the glass walls may, of course, be recovered completely, and thus another source of error avoided. The capillary tube $G$ may be fastened to $L^{\prime}$, if it is desired to transfer the gases to closed tubes in case the gases are to be preserved for a length of time.

We have found the following stopcock lubricant more satisfactory than the one described by Travers. I 8 grams of pure gutta-percha are added in small quantities to 26 grams of melted paraffin ( $m .70^{\circ}$ ) kept at a temperature of about $150^{\circ}$ until the gutta percha is dissolved. 20 grams of heavy mineral oil (that supplied with the Fleuss patent pumps answers admirably) are added and the whole maintained in an oven at a temperature of $125^{-1} 30^{\circ}$ for four or five hours.

BROWN UNIVERSTTY,

ProvideNCE, R. I.

[CONTRIBUTION FROM THE CHEMICAL LABORATORY OF THE UNIVERSITY OF WASHINGTON.]

ANALYSIS OF MIXTURES OF HALOGEN ACIDS. II. ${ }^{1}$

BY WILLIAM M. DERN.

Received September 15, 1909.

Most methods of analysis of mixtures of two halide ions require two gravimetric analyses. In addition, usually one distillation is required. The following described method involves one volumetric and one gravimetric determination for the estimation of the two ions.

An excess of silver nitrate is added and the precipitated silver salts are determined gravimetrically, best, of course, filtered and weighed in a Gooch funnel. The filtered solution, containing the excess of silver nitrate, is titrated with thiocyanate and ferric nitrate by the Volhard method.

Let $(a)$ equal the weight of silver nitrate required to precipitate both of the halogens present and let (b) equal the weight of the silver halides precipitated. Also let $(\mathrm{Cl}),(\mathrm{Br})$, and (I) equal the respective weights of the halogen ions contained in the sample analyzed. Then if the estimations are made with the same sample or if the estimations are calculated on the basis of the same sample, we have, in the case of chlorine and bromine, the equations

1 Thts Journal, 31, 525; vide also 3I, 1220 . 